\title{
Análise temporal da ocorrência de incêndios florestais nas Américas e região do Caribe
}

\author{
Elaine Cristina Gomes SILVA ${ }^{1}$, Nilton Cesar FIEDLER ${ }^{*}$, Ronie Silva JUVANHOL ${ }^{1}$, \\ Gabriel Mancini Antunes SILVA ${ }^{1}$, Felipe Patrício das NEVES ${ }^{2}$
}

\author{
${ }^{1}$ Centro de Ciências Agrárias e Engenharias, Universidade Federal do Espírito Santo, Jeronimo Monteiro, ES, Brasil. \\ ${ }^{2}$ Corpo de Bombeiros Militar do Espirito Santo, Serra, ES, Brasil. \\ *E-mail: fiedler@pq.cnpq.br
}

Recebido em novembro/2017; Aceito em maio/2018.

\begin{abstract}
RESUMO: Com as mudanças climáticas ocorridas nas últimas décadas e com longos períodos de estiagem, as chances de ocorrências de fogo com maior frequência e intensidade, aumentam e, sem o devido controle, acabam ocasionando grandes incêndios florestais. Como consequência, pode haver elevados prejuízos ao meio ambiente e à sociedade. Sabendo da importância das estatísticas sobre incêndios florestais, objetivou-se nesta pesquisa, analisar dados estatísticos publicados pela Food and Agriculture Organizacion of the United Nations - FAO, sobre as principais causas, ocorrências e áreas queimadas nas Américas do Norte, Central, Sul e Região do Caribe, no período de 1990 a 2004. Os dados foram tabulados de diferentes maneiras, a fim de produzir uma estatística única, de acordo com a série temporal proposta. Os países da América Central e Caribe são os que menos apresentaram dados disponíveis enquanto que, os Estados Unidos é o que apresenta maior base de dados estatísticos. Os resultados mostraram que a América do Sul tem as maiores médias, em comparação com as demais regiões, os Estados Unidos têm o maior quantitativo de ocorrências, existe forte influência de fenômenos como El Ninõ e que as atividades humanas foram responsáveis pela grande maioria das ocorrências de incêndios florestais.
\end{abstract}

Palavras-chave: proteção florestal, fogo, estiagem.

\section{Temporal analysis of the occurrence of forest fires in the Americas and the Caribbean region}

\begin{abstract}
With the climatic changes that occurred in the last decades and with long periods of drought, the chances of occurrences of fire with more frequency and intensity, increase and, without proper control, end up causing forest fires. As a consequence, there can be great damage to the environment and to society. The objective of this research was to analyze statistical data published by the Food and Agriculture Organization of the United Nations (FAO) on the main causes, occurrences and areas burned in North, Central, South and Central America of the Caribbean, from 1990 to 2004. Data were tabulated in different ways to produce a single statistic, according to the proposed time series. Central American and Caribbean countries are the least likely to have available data, while the United States has the largest statistical data base. The results showed that South America has the highest averages compared to the other regions, the United States has the highest number of occurrences, there is a strong influence of phenomena such as El Nino and that human activities were responsible for the great majority of forest fires.
\end{abstract}

Keywords: forest protection, fire, drought.

\section{INTRODUÇÃO}

O uso do fogo faz parte da evolução natural do homem. Contudo, esse é apontado pela maioria das pesquisas do mundo, como o principal agente causador da maioria dos incêndios florestais já registrados, de grandes proporções ou não. A "Food and Agriculture Organizacion of the United Nations" - FAO (2006a), afirma que 90\% dos incêndios florestais são causados, principalmente, pelas atividades humanas com o uso do fogo.

De acordo com Canzian et al. (2016), o incêndio florestal é um dos maiores causadores de prejuízos no triângulo da sustentabilidade no meio florestal, ou seja, proporciona prejuízos econômicos, sociais e ambientais.

Nos países em desenvolvimento, o uso do fogo, como queima ou queimada, ainda é considerado um método barato de preparo da terra para o plantio de determinadas culturas ou para limpeza de pastagens (TETO et al., 2010). Entretanto, por motivos como práticas inadequadas ou um simples descuido, o agente causador do fogo pode perder o controle, ocasionando, acidentalmente, um incêndio.

É importante elucidar que o fogo faz parte do processo natural do manejo em diversos tipos de ecossistemas e que as queimas controladas são importantes ferramentas de manejo para a vida silvestre, sendo desenvolvidas com êxito em distintos países e ecossistemas de todo o mundo, mas que, ao mesmo tempo, deve ser aplicada com rigoroso cuidado e estudos prévios adequados (SOARES et al., 2009). Contudo, salienta-se que, com as mudanças climáticas ocorridas nas últimas décadas e com longos períodos de estiagem, a tendência é aumentar a frequência e intensidade das ocorrências de fogo em função das altas temperaturas. Mesmo que muitos animais e plantas necessitem de fogo para sua sobrevivência, existem ecossistemas que são muito sensíveis ao fogo (KELLY; BROTONS, 2017).

De todo modo, os incêndios florestais, de causas propositais ou não, podem trazer grandes prejuízos ao meio ambiente, sociedade e economia, de diferentes maneiras. 
De acordo com Global Fire Monitoring Center - GFMC (2017) o rápido aumento do uso descontrolado do fogo, foi notado, globalmente, a partir da década de 80. Entre meados dos anos 90 e 2004, observou-se mudanças significativas nas ocorrências de incêndios florestais de intensidades extremas em algumas regiões do mundo, resultando na destruição de ecossistemas naturais, aliado às mudanças climáticas e secas extremas.

Para tanto, é sabido que as estatísticas referentes aos incêndios florestais são fundamentais para a eficácia da prevenção. Conforme Torres et al. (2017) dados históricos e um bom índice de previsão facilita políticas adequadas para a quantificação e distribuição dos recursos de prevenção, visando à redução das perdas e, consequentemente, dos prejuízos financeiros e ambientais advindos da ocorrência de eventos catastróficos. Além disso, de acordo com Ribeiro (2014) dados históricos contribuem para os estudos a partir de duas perspectivas: o número de ocorrências ou a área queimada. Se por um lado o número de ocorrências está relacionado com as causas dos incêndios, a área queimada traduz as variáveis de natureza física e da eficiência ou não dos métodos de combate.

Rodríguez et al. (2013) corroboram nessa questão, afirmando que a falta de informações sobre os incêndios pode levar a dois extremos: gastos muito altos em proteção, acima do potencial de dano, ou gastos muito pequenos, colocando em risco a sobrevivência das florestas.

Contudo, apesar desses sinistros, as estatísticas mundiais sobre incêndios florestais, ainda estão longe de serem definidas com precisão, em função da fragilidade ou ausência de registro das ocorrências de incêndios em muitos países. Tal situação é evidenciada pela "International Association of Fire and Rescue Services" - CTIF, que afirma sobre a diminuição de informações enviadas pelos países, cuja média era de 50 por ano em 1997-2001 para 33 por ano em 2011-2015 (CTIF, 2017). A FAO (2017) corrobora afirmando sobre a falta de dados capazes de gerar estimativas globais sobre as áreas florestais atingidas por incêndios.

Diante do exposto, o objetivo deste trabalho é analisar dados estatísticos da FAO sobre as principais causas, ocorrências e áreas queimadas por incêndios florestais, nas Américas do Norte, Central, Sul e Região do Caribe, no período de 1990 a 2004.

\subsection{Estudos da FAO}

A FAO avalia os recursos das florestas no mundo em intervalos de 5 a 10 anos, desde 1946, ano em que foi publicada a primeira avaliação, com o objetivo de elaborar uma série de estudos globais focados na interação entre pessoas e florestas, descrevendo a situação histórica das florestas no mundo e como essas estão mudando. A base de dados da FAO é constituída de duas fontes primárias: relatórios enviados pelos países membros, elaborados por correspondentes nacionais e dados de sensoriamento remoto conduzidos pela própria $\mathrm{FAO}$, com apoio de parceiros regionais (FAO, 2017).

Apesar da realidade das limitações das informações, as análises publicadas pela $\mathrm{FAO}$, apresentam considerável valor, pois possibilitam prever as mudanças ocorridas nos recursos florestais ao longo do tempo a nível global, dando indicação dos impactos na sociedade, economia e no meio ambiente. Estudos recentes de MacDicken (2015) demonstram a importância das informações publicadas pelos programas da
FAO e sua contribuição no cenário histórico dos recursos florestais globais, tanto em termos de seu conteúdo substantivo, como também nas necessidades de mudança no uso e manejo dos recursos florestais.

Salienta-se que não existem padrões estatísticos ou parâmetros estabelecidos pela FAO aos países-membros para a coleta de dados sobre incêndios florestais, cada país tem seu próprio método, informando apenas os resultados finais. A FAO justifica tal fato por compreender as dificuldades econômicas, sociais, ambientais e políticas de cada país, no qual as informações publicadas sobre os incêndios florestais não representam sua própria opinião e sim, informações oficiais apresentadas pelos países (FAO 2001).

\subsubsection{A Forest Resources Assessment (FRA)}

A FRA se baseia em respostas obtidas por meio de questionários, padronizados, enviados aos governantes ou correspondentes dos países membros, organizados por regiões geográficas.

Os questionários são constituídos por categorias de informação que apresentam o tipo do distúrbio ocorrido na floresta, número e extensão anuais, tais como: número de incêndios, área afetada e florestas afetadas por incêndios; área afetada por surtos de insetos; área afetada por surtos de doenças; área afetada por eventos climáticos severos; e área de floresta com cobertura de dossel reduzida (LIEROP, 2015).

\section{MATERIAL E MÉTODOS}

Esta pesquisa, classificada como documental, exploratória e descritiva, apresenta análise quantitativa do levantamento das estatísticas propostas, abordando, qualitativamente, aspectos dos índices nas regiões pesquisadas.

\subsection{Fonte de dados}

A base de dados para o desenvolvimento deste estudo foi obtida por meio dos documentos "Fire Management Global Assessment" e "Global Forest Resources Assessment", elaborados pelo programa da FAO "Forest Resources Assessment" (FRA). Alguns dados complementares foram levantados na "International Forest Fire News Country Notes" - IFFN, que é um núcleo de pesquisa da equipe de especialistas em incêndios florestais da FAO juntamente com "Global Fire Monitoring Center" (GFMC).

\subsection{Coleta e análise de dados}

Os dados foram obtidos em diferentes documentos das fontes supracitadas, sendo tabulados de diferentes maneiras, a fim de produzir uma estatística única, de acordo com a série temporal proposta (1990 a 2004), demonstrando os números totais de incêndios e áreas queimadas de todos os tipos de vegetação, seja em áreas públicas ou privadas. Os resultados são apresentados por países e por divisão do continente.

\section{3 Área de estudo}

A área de estudo corresponde aos países membros que compõem a América do Norte, América Central, Região do Caribe e América do Sul (Figura 1).

\subsubsection{América do Norte}

Constituída pelo Canadá, Estados Unidos e México. As terras da América do Norte incluem uma série de ecossistemas entre as florestas boreais do Alasca e Canadá e a vegetação subtropical no Sudeste dos EUA e México (IFFN, 2017b). 


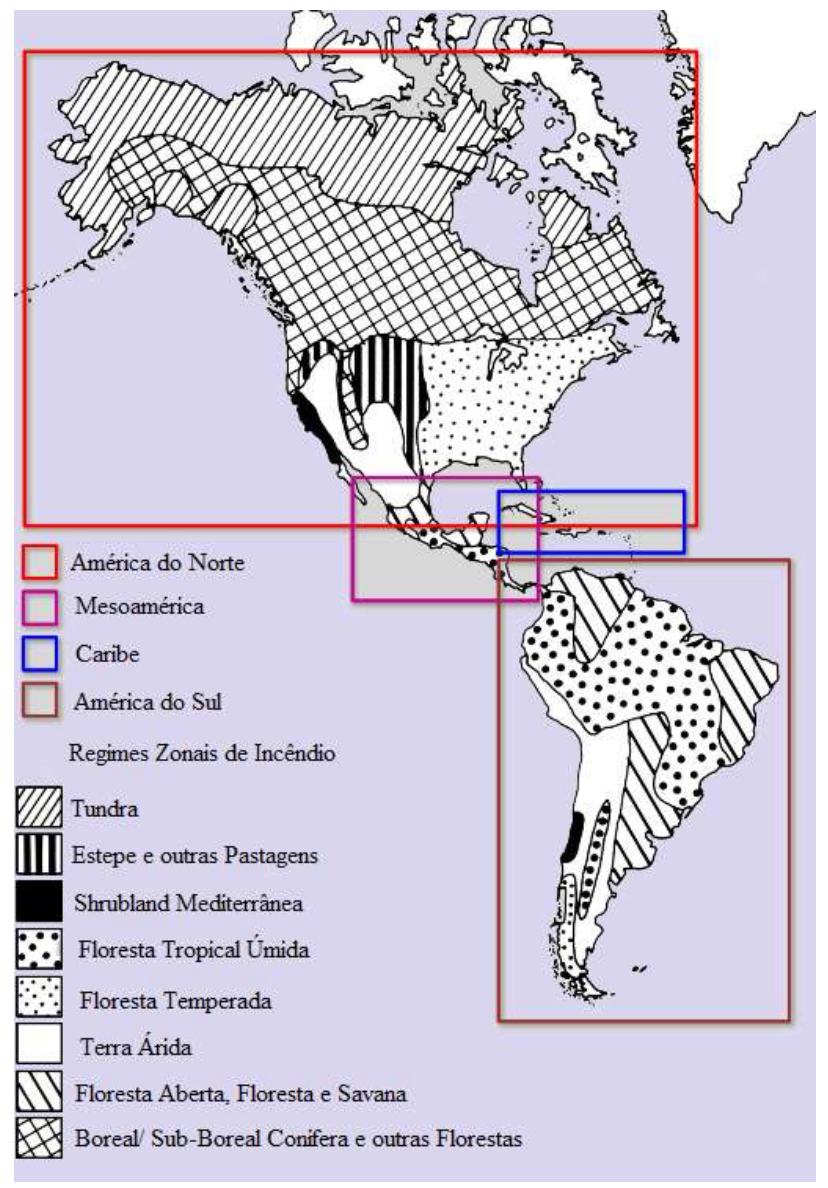

Figura 1. Áreas do estudo e seus respectivos Biomas. Figure 1. Study areas and their respective Biomes. Fonte: Adaptado de GFMC (2017).

\subsubsection{América do Norte}

Constituída pelo Canadá, Estados Unidos e México. As terras da América do Norte incluem uma série de ecossistemas entre as florestas boreais do Alasca e Canadá e a vegetação subtropical no Sudeste dos EUA e México (IFFN, 2017b). A FAO classifica o continente norte-americano em 15 regiões climáticas propícias a incêndios, com base em fatores geográficos e climáticos (FAO, 2011)

No Canadá, segundo IFFN (2017a) as florestas ocupam aproximadamente $40 \%$ da vasta paisagem canadense, cobrindo aproximadamente 417 milhões de hectares constituindo $10 \%$ do recurso florestal global. O fogo é natural nas florestas canadenses, particularmente na zona boreal, que detém $30 \%$ da floresta boreal do mundo, moldadas por incêndios periódicos por milênios. Neste ecossistema, o fogo é essencial na estrutura da paisagem, função e integridade ecológica.

\subsubsection{América Central}

Constituída por 20 países e 16 dependências, a América Central apresenta um clima tropical. A agricultura de subsistência é a atividade predominante, embora as culturas comerciais também sejam de importância para as economias nacionais. As terras da América Central incluem uma série de ecossistemas, desde florestas tropicais úmidas, nas regiões mais elevadas, a floresta aberta e savana, nos planaltos áridos da Guatemala, Honduras e El Salvador. Possui grande variedade de clima, topografia e tipos de florestas, incluindo esfregaço desértico e floresta tropical de terras baixas (FAO, 2006b).

A maioria dos países da América Central foi afetada pelos efeitos da seca em 1998 causada pelo El Niño.

\subsubsection{Caribe}

Essa região inclui cerca de 22 Estados insulares com tamanhos entre 110 e $110.000 \mathrm{~km}^{2}$. Apesar de serem em sua maioria, pequenos em comparação com os estados continentais mesoamericanos, seus recursos apresentam importante papel na economia, pois muitas ilhas dependem do turismo como fonte principal de renda.

Existem vários tipos de vegetação nas ilhas que respondem de forma diferente aos incêndios florestais, sendo agrupados da seguinte forma (FAO, 2006b):

- Vegetação mantida por incêndios naturais: floresta de pinheiros nas Bahamas e República Dominicana; vegetação sensível a incêndios selvagens e susceptível de causar dano de fogo (plantações florestais de espécies introduzidas como o Pinho do caribe e a Teca); florestas inundadas em Guadalupe em condições excepcionais de clima seco; florestas decíduas secas; manguezais em transição para a floresta interior;

- Vegetação independente do fogo: florestas montanas; florestas montanas úmidas em maiores elevações e manguezais em zonas de maré.

O clima dessa região é insular, determinado pelo movimento intertropical da zona de convergência com ventos predominantes e pela topografia. As áreas montanhosas são mais úmidas do que as terras baixas (FAO, 2001). De acordo com IFFN (2007) a estação do fogo em todos os países da região é definida pela estação seca e é apresentado de forma comum durante os primeiros cinco meses do ano. Os incêndios florestais ocorrem principalmente em florestas com características seca, com precipitação média anual de 1.000 a $1.500 \mathrm{~mm}$ e onde estão localizados a maioria dos assentamentos (FAO, 2006b).

\subsubsection{América do Sul}

Conforme IFFN (2007) os incêndios florestais nessa região ocorrem de formas bastantes diferentes entre os países devido principalmente a: diferenças climáticas, vegetativas, orográficas, dos níveis culturais e do comportamento das populações humanas existentes. Mesmo dentro do mesmo país, podem ser observadas diferenças significativas.

As florestas temperadas estão localizadas principalmente na Argentina, Chile, Paraguai e sul do Brasil. A vegetação regional varia de áreas praticamente não vegetativas no Deserto de Atacama para vegetação exuberantemente e abundante nas partes mais úmidas da floresta amazônica (FAO, 2006a).

A Bacia amazônica contém a maior floresta tropical do planeta, com quase 5,8 milhões de $\mathrm{km}^{2}$ e ocupa cerca de $40 \%$ do território da América do Sul. Mais de $60 \%$ da bacia está localizada no Brasil e o restante na Bolívia, Colômbia, Equador, Guiana Francesa, Guiana, Peru, Suriname e Venezuela. Em geral, o período normal de ocorrência de incêndios varia de acordo com o início e o fim do período chuvoso. Não foram encontrados dados quantitativos sobre as ocorrências de incêndios florestais na Guiana Francesa e Suriname. Os dados da Bolívia, do Equador e do Paraguai foram considerados como imprecisos nos documentos analisados. 


\section{RESULTADOS}

Os países da América Central e Caribe são os que menos apresentaram dados disponíveis.

A principal causa de ocorrência dos incêndios florestais de todo o período pesquisado foi por causas humanas, associado a limpeza de áreas agrícolas, pastagens para manejo de gado, extração de produtos florestais não-madeireiros, desenvolvimento industrial, reassentamento em área rural e caça, variando, marcadamente, em diferentes regiões (FAO, 2001).

Destaca-se que houve a ocorrência do fenômeno El Ninõ, com características diferenciadas conforme região e em alguns anos do período pesquisado, mas especificamente: 1990-1993 (forte intensidade); 1994-1995 (moderada intensidade); 1997 1998 (forte intensidade); 2004-2005 (fraca intensidade), conforme o Instituto Nacional de Pesquisas Espaciais - INPE (2017).

Eventos de El Ninõ são caracterizados por aquecimento anormal no Oceano Pacífico equatorial, influenciando as condições climáticas globais, ocorrendo em períodos irregulares.

Não foram encontradas nas áreas de estudo, os meses específicos que são mais propensos a ocorrência de incêndios.

Notou-se que as diferentes capacidades econômicas de cada país interferiram para a implementação de programas de gerenciamento de incêndios.

\subsection{América do Norte}

Os resultados do Canadá são apresentados isoladamente, pois não foram encontrados dados numéricos anuais para elaboração das estatísticas (Figura 2). Embora as estatísticas do Canadá se iniciam a partir da década de 60, são consideradas para este estudo as estatísticas a partir de 1990, a fim de padronizar o período pesquisado. A década de 90 começa com registros bem menores do que o ano anterior, que teve o maior índice registrado no período.

As regiões do Canadá e Federação Russa, são os únicos países no mundo onde o raio é a principal causa de incêndios florestais. O Canadá tem $85 \%$ dos seus incêndios ocasionados por relâmpagos (FAO, 2001).

De acordo com a FAO (2006c), os sofisticados sistemas de supressão de incêndios do Canadá são amplamente bemsucedidos, na medida em que a grande maioria dos incêndios (cerca de 97\%) são controlados em estágio inicial (queimam menos que 200 hectares). No entanto, aproximadamente $3 \%$ dos incêndios que excedem 200 hectares, representam cerca de $97 \%$ da área total queimada.

Os Estados Unidos possuem estatísticas históricas de incêndios florestais de grande potencial destrutivo há mais de cem anos. Como exemplo, em 1990, na Califórnia, queimaram 280 casas em uma média de três horas, com cerca de 120 novos focos de incêndios por dia, três anos depois. Pela primeira vez na história dos EUA, foi gasto US\$ 1 bilhão em supressão, com aproximadamente $25 \mathrm{mil}$ bombeiros, 900 motores, 155 helicópteros, 54 petroleiros e 31 cozinhas móveis (IFFN, 2017b).

A Figura 3 apresenta as estatísticas totais das ocorrências e áreas queimadas no México e Estados Unidos. Nesses dois países, $84 \%$ das causas dos incêndios foram por causas humanas, $14 \%$ por causas desconhecidas e $2 \%$ por causas naturais.

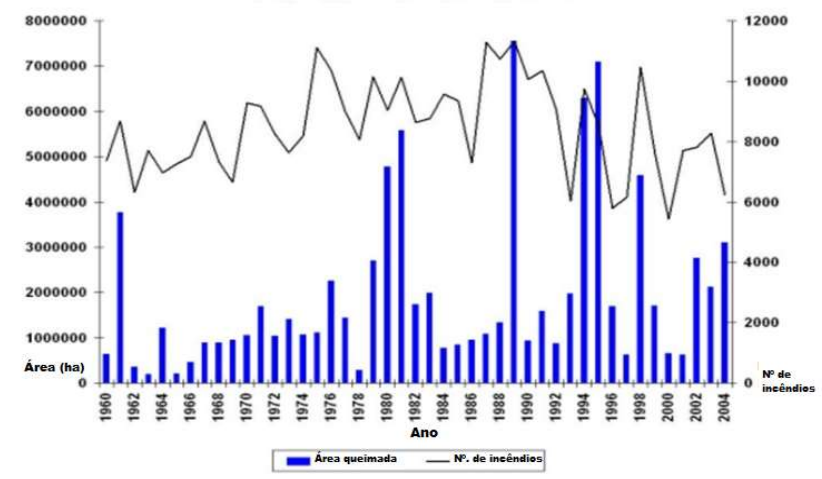

Figura 2. Números totais de incêndios e áreas queimadas no Canadá no período de 1960 a 2004

Figure 2. Total numbers of fires and burned areas in Canada from 1960 to 2004. Fonte: FAO (2006c, p.6).

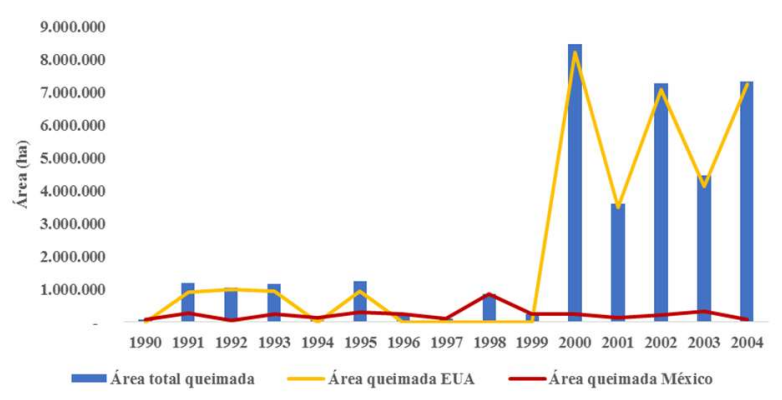

Figura 3: Total áreas queimadas nos Estados Unidos e México. Figure 3: Total burned areas in the United States and Mexico. Fonte: Elaborado pelos autores a partir dos dados de FAO (2001; 2006c).

No que tange ao México, a média anual de ocorrências de incêndios florestais foi de aproximadamente 7.689 focos com cerca de 233.456 hectares queimados por ano. Os maiores registros ocorreram em 1993 e 1998, anos de ocorrência de $E l$ Niño, de forte intensidade. Contudo, 1998 foi o maior registro tanto para o número de incêndios (14.445 focos) quanto para área queimada (849.632ha).

Os Estados Unidos detêm quase 90\% de todos os índices de incêndios florestais da América do Norte, apresentando ainda, a maior média anual do número de incêndios (103947 focos). A média anual de áreas queimadas chega a 2.261.184 hectares, e o período de 2000 a 2004 apresenta as maiores estatísticas de áreas queimadas, destacando-se o ano de 2000, que representa $24,23 \%$ para todo o período pesquisado, com 8.218.844 hectares.

\subsection{América Central}

Somente os países apontados na Figura 4 possuem informações sobre área total queimada ( 7 dos 21 países dessa região). Não foram encontrados dados sobre o número total de ocorrências de incêndios florestais nesses países.

O ano de 1998 registrou 45,9\% de áreas queimadas. El Salvador tem o menor índice médio anual de áreas queimadas com 2.330 hectares. Já a Guatemala apresenta o maior registro com 89.316 hectares queimados anualmente. O período de abril a maio foi considerado o mais crítico de riscos de incêndios para essa região. 


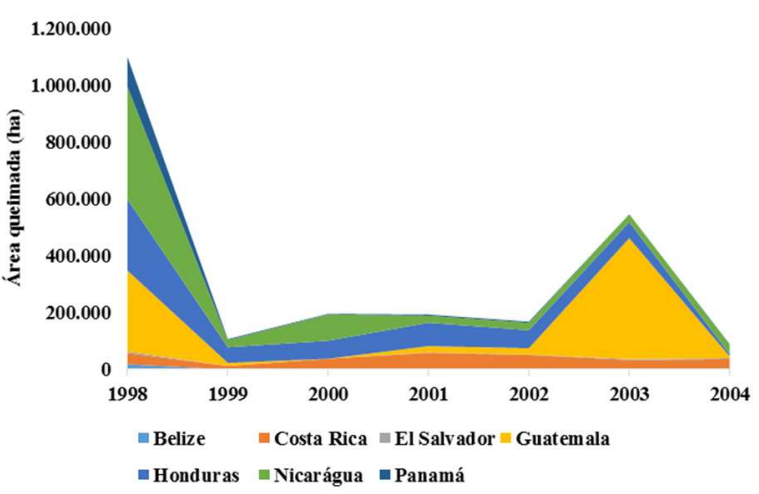

Figura 4. Área total queimada na América Central.

Figure 4. Total area burned in América Central.

Fonte: Elaborado pelos autores a partir de FAO (2001; 2006b).

As florestas de Belize, são seriamente afetadas pela exposição prolongada à tempestades e furacões, que contribuem para criar alto risco de material combustível.

FAO (2006b), afirma que, em Honduras e Nicarágua, os incêndios são considerados de baixa intensidade, mas os períodos sem fogo rapidamente levam a acumulação de material combustível perigoso e que os incêndios pioraram após a introdução do pasto africano na região. Contrastando com a Guatemala e a Nicarágua, onde o raio é uma causa regular de ignição mais abundante no nordeste da região.

Na Guatemala em 1998, o fenômeno El Niño causou seca e altas temperaturas, influenciando o surgimento de vários incêndios. Tal situação, motivou inúmeras organizações a melhorarem os registros dos dados de incêndios. Embora o número de incêndios tenha aumentado em 2000, sua extensão e quantidade de incêndios reduziram nos anos seguintes.

De acordo com FAO (2006b) muitas informações provenientes da Guatemala, Honduras e Nicarágua carecem de credibilidade e precisam ser verificadas. O IFF (2007) afirma que devido às limitações políticas, muitas iniciativas na Mesoamérica não alcançam resultados concretos.

\subsection{Caribe}

Somente poucos países apresentam alguns dados que contemplam parte do período pesquisado (2003 e 2004), como visto na Tabela 1. Segundo (FAO, 2006b) tais informações, só foram disponibilizadas pelos países que participaram da $12^{\mathrm{a}}$ Reunião de Foresters do Caribe, realizada em 2004.

Cuba é o país que mais apresenta dados estatísticos completos dessa região e os maiores registros tanto em número de incêndios quanto em áreas queimadas.

A República Dominicana segue logo após Cuba em termos de estatísticas mais completas da Região do Caribe e, em 10 anos, teve cerca de 324.000 incêndios a menos do que Cuba. Entretanto, a área queimada foi maior no período de 14 anos de Cuba. Apresentou apenas $5 \%$ de incêndios causados por raios. Em Trindade, o ano de 2003 foi considerado a pior estação seca do período apresentado.

\subsection{América do Sul}

A Figura 5 apresenta o número total de incêndios na América do Sul e o total de áreas queimadas.

A média anual de registros de incêndios para todo o período pesquisado é de 16.262 e média de 3.290 .263 hectares queimados anualmente. No ano de 1997, foram 66.807 ocorrências de incêndios, contribuindo com cerca de
5.585.369 hectares queimados, perfazendo $27 \%$ do total de áreas queimadas, para o período. Só no estado de Roraima, no Brasil, Barbosa e Fearnside (1999) estimaram cerca de 278.000 hectares de áreas queimadas, em 1997. Ressalta-se que não foram encontrados dados nas fontes de pesquisa sobre os índices anuais do Brasil para o ano de 1999.

Em 1999, em toda a América do Sul, foi registrado apenas o equivalente a $2 \%$ do total do número de incêndios. Entretanto, ocasionou 13.592.352 hectares queimados, o maior índice do período para áreas queimadas nessa região, com $28 \%$. O segundo maior registro ocorreu em 2003, com cerca de 6.116 .558 hectares queimados. Portanto 55\% menos áreas queimadas do que o maior registro, em 1997.

A Argentina, Bolívia e Brasil destacam-se com as maiores estatísticas da década de 1990. Em geral, a situação dos incêndios florestais mais graves foi apontada para o Brasil, Bolívia, Venezuela, Colômbia, Equador, Paraguai e Peru. Já o Uruguai apresentou índices bem menores. Conforme FAO (2001), todos os anos, a Bolívia, Brasil, Paraguai e Argentina, são os mais afetados por muitos incêndios florestais resultantes do preparo de terras para agricultura e pecuária, especialmente no período de queima, que começa com a estação seca e se estende de junho a novembro, dependendo do regime particular de precipitação do ano.

Tabela 1. Estatísticas disponibilizadas sobre área queimada da região do Caribe.

Table 1. Statistics made available on the burned area of the Caribbean region.

\begin{tabular}{|c|c|c|c|}
\hline \multirow[t]{2}{*}{ País } & $\begin{array}{c}\mathrm{n}^{\mathrm{o}} \text { incêndios(i) e } \\
\text { área queimada } \\
\text { (ha) }\end{array}$ & $\begin{array}{l}\mathrm{n}^{\mathrm{o}} \text { incêndios (i) } \mathrm{e} \\
\text { área queimada } \\
\text { (ha) }\end{array}$ & $\begin{array}{c}\text { Área } \\
\text { queimada } \\
\text { (ha) }\end{array}$ \\
\hline & $\begin{array}{c}\text { Anos } \\
1990 \text { a } 1999\end{array}$ & Ano 2003 & Ano 2004 \\
\hline Bahamas & - & - & 300 \\
\hline Cuba & $\begin{array}{c}325.000 \text { (i) } \\
4.878 \text { (ha) }\end{array}$ & 6.000 & 12.900 \\
\hline Dominica & 1.343 (i) & 800 & 3000 \\
\hline Haiti & - & - & 100 \\
\hline $\begin{array}{l}\text { República } \\
\text { Dominicana }\end{array}$ & $\begin{array}{c}86 \text { (i) } \\
6.031 \text { (ha) }\end{array}$ & 800 & 300 \\
\hline Trinidade & $\begin{array}{c}3.159 \text { (i) } \\
2.114 \text { (ha) }\end{array}$ & $\begin{array}{c}347 \text { (i) } \\
4.723 \text { (ha) }\end{array}$ & 100 \\
\hline
\end{tabular}

Fonte: Elaborado pelos autores a partir de FAO (2015).

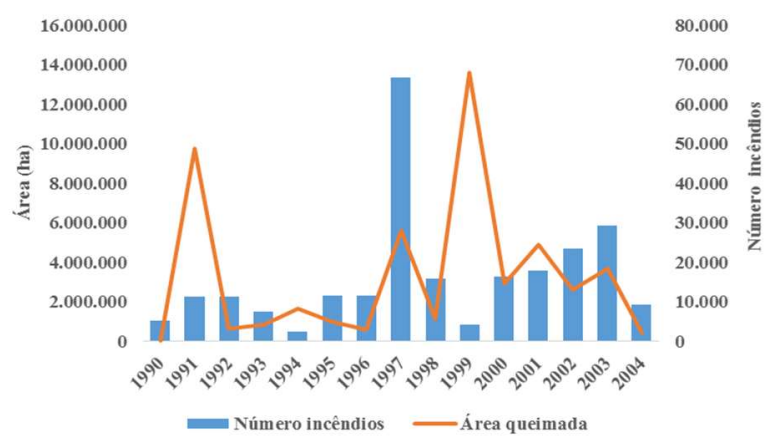

Figura 5. Número total de incêndios na América do Sul e o total de áreas queimadas.

Figure 5. Total number of fires in South America and the total number of areas burned.

Fonte: Elaborado pelos autores a partir de FAO (2006a). 
Observou-se que somente alguns países possuem sistemas estatísticos nacionais que operam com informações completas e confiáveis sobre incêndios florestais. Quase metade dos países não tem informação disponível, ou não é publicado (IFFN, 2007). No norte da Argentina, Chile, Colômbia, Bolívia, Brasil, Equador e Peru, os incêndios ocorrem sobretudo no outono e inverno (FAO, 2017).

\section{DISCUSSÃO}

A América do Sul tem as maiores médias anuais tanto para número de incêndios quanto para área queimada, em comparação com as demais regiões. Em termos de país, os Estados Unidos têm a maior média.

Destaca-se que cada país e região possuem características próprias, o que faz perceber grandes diferenças nas estatísticas de cada país. Para Nunes et al. (2015) as causas dos incêndios, além de diferirem de país para país, são também espacialmente diferentes dentro do mesmo país, pois depende de um conjunto específico de fatores regionais, associados não só aos componentes ambientais, como as condições climáticas, o relevo, as caraterísticas dos combustíveis, entre outras, mas, também, às atitudes e os comportamentos humanos.

Foi observado que as estatísticas mais elevadas ocorridas nos anos 1993, 1997, 1998, 1999, 2003 e 2004, foram em períodos de ocorrência de El Niño (ou bem próximos). Todas as regiões pesquisadas apresentaram, em algum desses anos, os maiores índices, quer seja de número de incêndios ou área queimada, exceto os Estados Unidos, que apresentou os maiores índices no ano 2000.

No que tange a América Central e a região do Caribe, notou-se que, a grande maioria dos incêndios ocorrem em períodos onde a estação seca é mais comum. Em função da fragilidade dos dados, os governos dos países que compõem essas regiões precisam aprimorar suas informações oficiais sobre incêndios florestais, até mesmo para elaborar suas próprias políticas de prevenção e combate. Sobre tais regiões, existe uma elevada carência de políticas eficazes de prevenção e combate a incêndios (FAO, 2006b). Um estudo sub-regional realizado por Schindler et al. (2002) afirma que as estatísticas sobre incêndios florestais na Guatemala, Honduras e Nicarágua são insuficientes, sendo necessário analisar os fatores socioculturais locais e propor medidas.

Em geral, a maioria das causas dos incêndios florestais nos países estudados (exceto o Canadá) são iniciados por atividades humanas, mesmo que muitas dessas ocorrências não tenham sido de modo intencional, mas, sim, como resultado de ações motivadas pela desigualdade social, desvalorização dos recursos naturais, cultura e educação ambiental, falta de políticas e de manejo dos recursos florestais pelas comunidades, como apontado pela FAO (2001).

É importante ressaltar que as estatísticas apresentadas neste estudo não representam os totais reais dos países supracitados, e sim demonstram as estatísticas oficiais fornecidas pelos países membros à FAO. Contudo, o estudo é um importante esforço para delinear o perfil dos incêndios nas regiões estudadas dada as incipientes estatísticas.

\section{CONCLUSÕES}

A América do Sul tem as maiores médias anuais tanto para número de incêndios quanto para áreas queimadas, em comparação com as demais regiões. Em relação ao país, os Estados Unidos têm a maior média de ocorrências e apresenta uma maior base de dados estatísticos dos incêndios florestais.
Os anos com ocorrência do fenômeno El Ninõ foram associados, em geral, a maiores índices de ocorrências de incêndios florestais nas regiões estudadas.A maior causa de incêndios florestais no Canadá é natural, ocasionado por raios. Nas demais regiões, a causa principal é a atividade humana, como resultado de questões sociais, culturais e políticas.

As estatísticas de ocorrência de incêndios florestais podem contribuir para dar suporte às políticas públicas, pelo conhecimento das épocas de maior ocorrência de incêndios e mudanças ocorridas ao longo do tempo.

\section{REFERÊNCIAS}

BARBOZA, R. I.; FEARNSIDE, P.M. Incêndios na Amazônia brasileira: estimativa da emissão de gases do efeito estufa pela queima de diferentes ecossistemas de Roraima na paisagem do evento "El Niño" (1997/98). Acta Amazônica, Manaus, v. 29, p. 513-534, 1999.

CANZIAN, W. P.; FIEDLER, N. C.; BRINATE, I. B.; JUVANHOL, R. S.; BIGHI, K. N. Diferentes concentrações de retardante de fogo em plantios de eucalipto. Nativa, Sinop, v.4, n.4, p.195-198, 2016. DOI: 10.14583/2318-7670.v04n04a02.

FOOD AND AGRICULTURE ORGANIZACION OF THE UNITED NATIONS (FAO). Global Forest Fire Assessment 1990-2000. Roma, 2001. 495 p. Global Forest Resources Assessment 2005: Report on fires in the South American Region. Roma, 2006a. 42 p. Global Forest Resources Assessment 2005: Report on fires in the Caribbean and Mesoamerican Regions. Roma, 2006b. 40 p.

Global Forest Resources Assessment 2005: Report on fires in the North American Region. Roma, 2006c. 37 p.

GLOBAL FIRE MONITORING CENTER (GFMC). Vegetation Fires and Global Change. Challenges for Concerted International Action. A White Paper directed to the United Nations and International Organizations. Germânia, 2013. Disponível em: < http://www.fire.unifreiburg.de/latestnews/Vegetation-Fires-Global-ChangeUN-White-Paper-GFMC-2013.pdf>. Acesso em: 08 set. 2017.

INTERNATIONAL ASSOCIATION OF FIRE AND RESCUE SERVICES (CTIF). Center of fire statistics. World fire statistics. $n^{\circ} 22$, National committees CTIF of Russia, Germany, USA, 2017. Disponível em: < http://www.ctif.org/sites/default/files/ctif_report22_world fire_statistics_2017.pdf $>$. Acesso em: $1 \overline{5}$ set. $201 \overline{7}$.

INSTITUTO NACIONAL DE PESQUISAS ESPACIAIS (INPE). El Niño e La Niña. Disponível em:< http://enos.cptec.inpe.br/>. Acesso em: 15 set. 2017.

INTERNATIONAL FOREST FIRE NEWS COUNTRY NOTES (IFFN). Forest Fire Management in Canada. Disponível em: < http://www.fire.unifreiburg.de/iffn/country/ca/ca_7.htm >. Acesso em: 12 set. $2017 \mathrm{a}$.

Fire Situation in the United States. n. 27 - Jul. 2002, p. 6-13). Disponível em: < http://www.fire.unifreiburg.de/iffn/country/us/us_17.htm>. Acesso em: 19 mai. $2017 b$.

Evaluación del Fuego en la Región de Latinoamérica: Mesoamérica, Caribe y América del Sur Conclusiones y Recomendaciones. Espanha, nº. 36, p. 6-9, Jan./Jul, 2007. 
KELLY, L. T.; BROTONS, L. Using fire to promote biodiversity. Science, v. 355, p. 1264-1265, mar, 2017. DOI: $10.1126 /$ science.aam7672

LIEROP, P. V.; LINDQUIST, E.; SATHYAPALA, S.; FRANCESCHINI, G. Global forest area disturbance from fire, insect pests, diseases and severe weather events. Forest Ecology and Management, v. 352, p. 78-88, 2015. DOI: http://dx.doi.org/10.1016/j.foreco.2015.06.010.

MACDICKEN, K, G. Global Forest Resources Assessment 2015: What, why and how? Forest Ecology and Management, v. 352, p. 3-8, 2015. DOI: http://dx.doi.org/10.1016/j.foreco.2015.02.006.

NUNES, A.; LOURENÇO, L.; LU, S. O.; FELIX, F. Vulnerabilidade a incêndios na Europa Mediterrânea. Abordagem conceptual e a utilização de dados de satélite. In: Atas das I Jornadas Lusófonas de Ciências e Tecnologias de Informação Geográfica. Sessão 5, Artigo 18, Coimbra, Portugal 2015. DOI: http://dx.doi.org/10.14195/978-989-26-0983-6_18.

PEREIRA, F. J., BATISTA, A. C., SOARES, R. Variação da umidade do material combustível florestal em função de índices de perigo de incêndios. Cerne, Lavras, v. 18, n. 3, p. 371-376, 2012.

RIBEIRO, M. I. M. Prevenção e detecção de incêndios florestais: Análise holística e sistemas tecnológicos. 2014. 140 f. Dissertação (Mestrado em Engenharia do ambiente). Universidade do Porto, Porto, 2014.
RODRÍGUEZ, M. P. R.; SOARES, R. V.; BATISTA, A. C.; TETTO, A. F.; BECERRA, L. W. M. Comparação entre o perfil dos incêndios florestais de monte alegre, Brasil, e de pinar Del Rio, Cuba. Floresta, Curitiba, v. 43, n. 2, p. 231 - 240, 2013. DOI: http://dx.doi.org/10.5380/rf.v43i2.

SCHINDLER, L.; FLACHSENBERG, H.; ROMERO, F. Incendios Forestales en Guatemala, Honduras y Nicaragua - Análisis de la situación presente y acciones a seguir. GTZ, Germany, 2002.

SOARES, R. V. Perfil dos incêndios florestais no Brasil, de 1984 a 1987. Floresta, Curitiba, v. 32, n. 2, p. 219-232, 1988.

SOARES, R. V.; BATISTA, A. C.; NUNES, J. R. S. Incêndios florestais no Brasil: o estado da arte. Curitiba: 2009. 246p.

TETO, A. F.; BATISTA, A. C.; NUNES, J. R. S.; SOARES, R. V. Subsídios à prevenção e combate a incêndios florestais com base no comportamento da precipitação pluviométrica na floresta nacional de Irati, Paraná. Ciência Florestal, Santa Maria, v. 20, n. 1, p. 33-43, 2010.

TORRES, F. T. P.; LIMA, G. S. L.; MARTINS, S. V.; VALVERDE, R. V. Analysis of efficiency of fire danger indices in forest fire Prediction. Revista Árvore, Viçosa, v. $41, \quad$ n. 2 , p. $1-10,2017$. DOI: http://dx.doi.org/10.1590/180690882017000200009. 